\title{
THE EFFECT OF CONTINUOUS NEGATIVE PRESSURE BREATH- ING ON WATER AND ELECTROLYTE EXCRETION BY THE HUMAN KIDNEY
}

\author{
BY HERBERT O. SIEKER,1 OTTO H. GAUER,2 AND JAMES P. HENRY \\ (From the Aero-Medical Laboratory, Wright-Patterson Air Force Base, Ohio)'
}

(Submitted for publication September 4, 1953; accepted December 30, 1953)

The effects of decreased intrathoracic pressure on arterial blood pressure (1), venous pressure $(2,3)$, cardiac output $(4)$, and pulmonary pressure and volume (5) have been investigated in the past. The present study was prompted by the association of marked diuresis with continuous negative pressure breathing in anesthetized animals (6) and the observation that in unanesthetized man continuous positive pressure breathing leads to an oliguria (7). The purpose of this investigation was to demonstrate that human subjects like anesthetized animals have an increased urine flow in response to continuous negative pressure breathing. Observations were made on the renal excretion of water, sodium and potassium, urinary $\mathrm{pH}$, and endogenous creatinine clearance in the hope that the mechanism of the diuresis might be elucidated.

\section{METHODS}

Sixteen experiments and six control studies were done with eight normal males who ranged in age from 18 years to 43 years. The subjects received their usual breakfast without added salt on the morning of the experiment. The study was carried out with the subject in the recumbent position in a constant temperature environment. In order to obtain an adequate urine volume and a steady state, each subject was maintained on $50 \mathrm{cc}$. and in some cases $100 \mathrm{cc}$. of 0.14 per cent saline by mouth (8) every half hour of the experiment which was started with the intake of $300 \mathrm{cc}$. of this hypotonic solution. In addition each subject had one chocolate bar every two to three hours.

Voided urine samples were obtained at 15-minute intervals while in the recumbent position. Individuals who were unable to void voluntarily at this interval were not used in the study. Negative pressure breathing was not begun before a urine flow consistently below $60 \mathrm{cc}$. per 15 minutes (in most cases 15 to $30 \mathrm{cc}$. per 15 minutes) was obtained for a two to four-hour period. This was usually five to seven hours after the start of the experi-

\footnotetext{
1 Present Address : Department of Medicine, Duke University School of Medicine, Durham, North Carolina.

2 Present Address: Department of Physiology, Duke University School of Medicine, Durham, North Carolina.
}

ment. Negative pressure breathing during both inspiration and expiration was applied through a standard U. S. Air Force pressure breathing oxygen mask attached by a short tubing to a 40 liter cylinder. This cylinder was ventilated by a suction pump with fresh air at the rate of 100 to 160 liters per minute and rebreathing was prevented by means of a two-way valve in the face mask. The desired negative pressure, which in these experiments was a mean pressure of 15 to 18 centimeters of water, was obtained by varying the air inlet to the container. Control studies duplicated the procedure exactly except that the negative pressure breathing was omitted. $\mathrm{Re}$ peat studies were done in all but two subjects.

The urine volume for each 15-minute interval was noted and the $\mathrm{pH}$ of each sample was determined by means of a glass-calomel electrode $\mathrm{pH}$ meter which had an accuracy of $0.1 \mathrm{pH}$ units. Sodium and potassium determinations were made on each urine specimen with an internal standard Perkin Elmer flame photometer. The endogenous creatinine content of the blood and urine was measured by the method of Bonsnes and Taussky (9). The creatinine clearance was used for convenience in these studies with an awareness of both its accuracy and its limitations. The pulse and respiratory rates were followed and periodic observations of the blood pressure were made with a standard sphygmomanometer.

\section{RESULTS}

An example of the diuresis observed with continuous negative pressure breathing is presented in Figure 1. The 15-minute urine volume increased about 300 per cent with this type of respiration following a control period of six hours in which the urine flow was consistently under $35 \mathrm{cc}$. per 15 minutes the last two to three hours. Moreover, within 30 minutes after the cessation of negative pressure breathing, the urine flow had returned to its control value. A spontaneous diuresis was not observed in the six control studies during the portion of the day when negative pressure breathing was ordinarily done in the experimental studies, although in both the control and experimental observations a diuresis was noted in the early portion of the day (Figure 1). This initial diuresis was attributed to the diurnal variation, the post- 


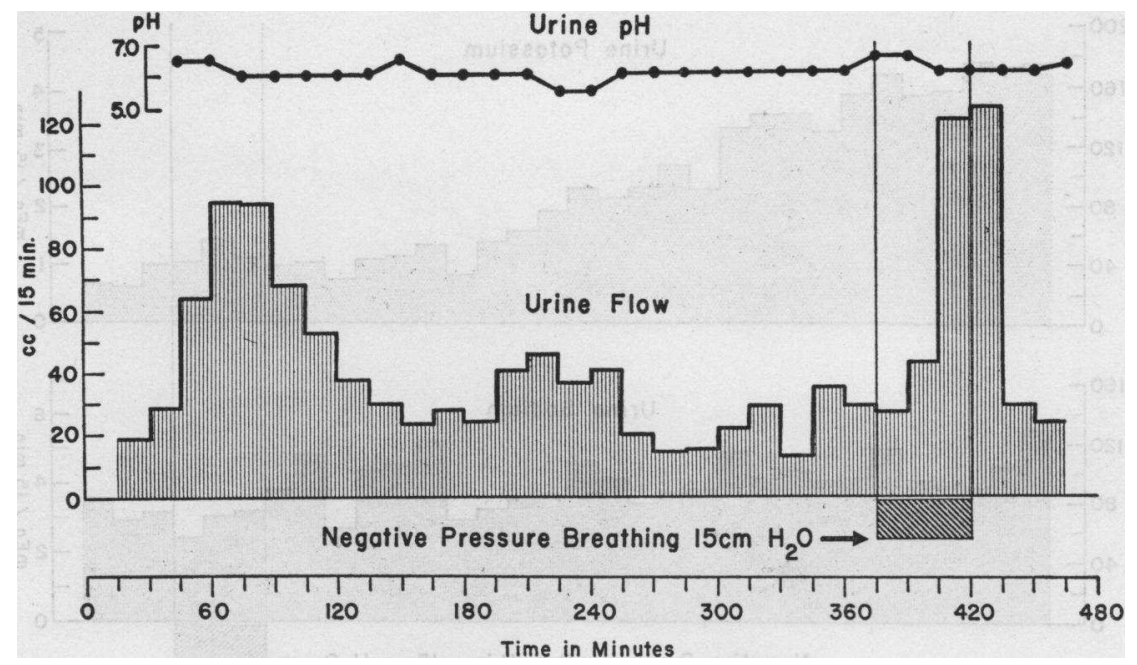

Fig. 1. An Example of the Diuresis Observed with Negative Pressure Breathing Note the essentially unaltered urine $\mathrm{pH}$ during the diuresis. (Subject E. M.)

prandial state, the change from the erect to the recumbent position, and the ingestion of $300 \mathrm{cc}$. of hypotonic saline solution.

The concentration of both the sodium and potassium in the urine decreased during the episode of negative pressure breathing, so that the total amount of these two electrolytes excreted during that period did not exceed the amount excreted during a control period of the same duration. This is demonstrated in Figure 2 where the total sodium excreted for the 45 minutes of negative pressure breathing did not exceed that excreted during the preceding or succeeding 45 minutes. Similarly, the total excretion of potassium as plotted in Figure 3 did not increase when the intrathoracic pressure was decreased. In this particular example the urine flow had increased about four fold in the last 15 minutes of the experimental breathing while the sodium and potassium excretion remained unaltered.

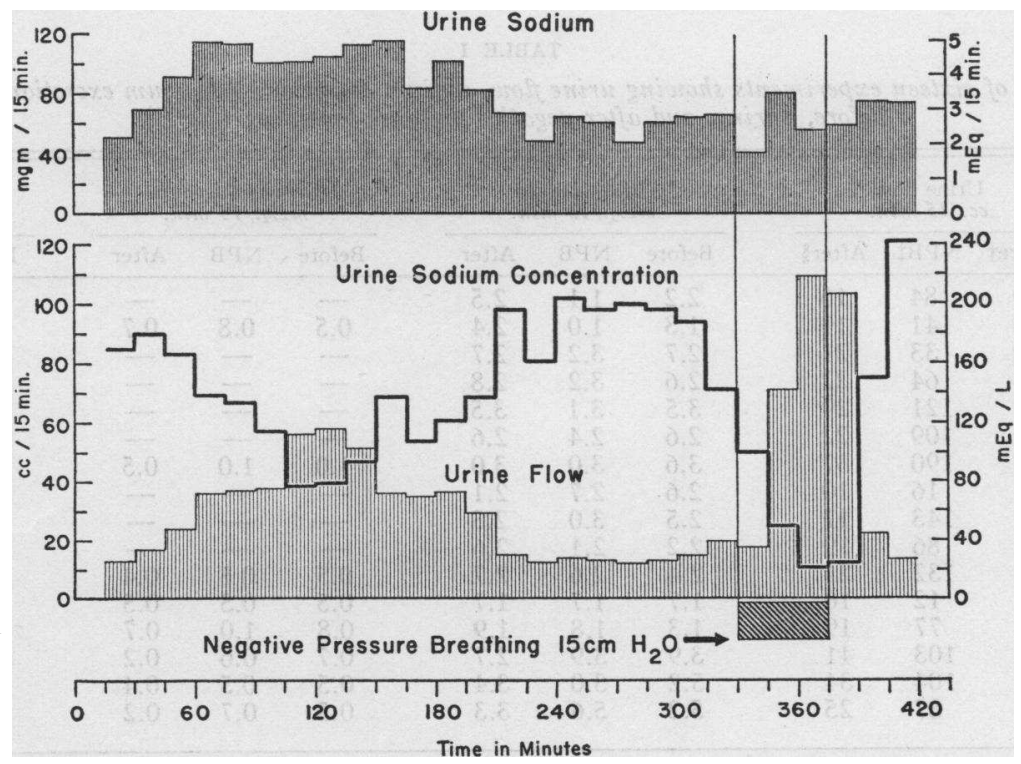

Fig. 2. An Illustration of the Unchanged Excretion of Total Sodium in the Urine during a Period of Negative Pressure Breathing (SubJect E. M.*) 


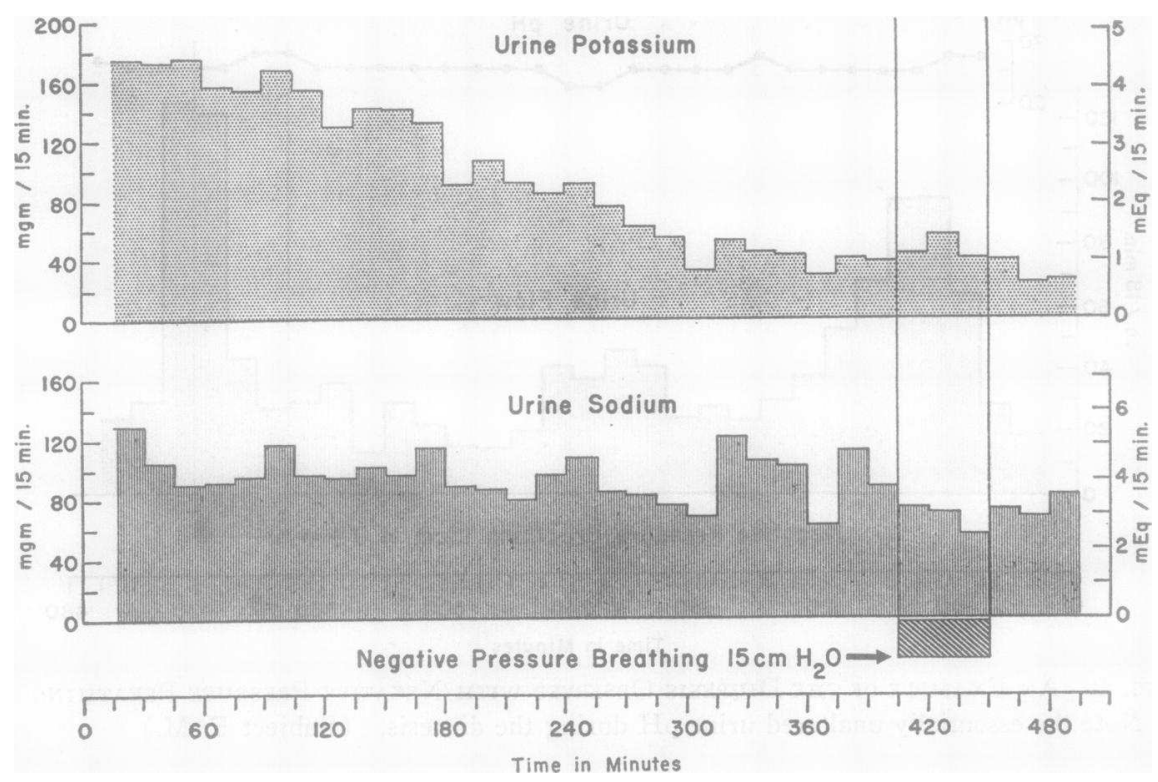

Fig. 3. Effect of Negative Pressure Breathing on the Total Excretion of Sodium AND Potassium

In this example the urine flow increased about four fold during the period of decreased intrathoracic pressure. (Subject E. M.*)

The results of urine volume and electrolyte determinations in the sixteen experiments are summarized in Table I. Six of the eight subjects exhibited a moderate to marked diuresis when the intrathoracic pressure was decreased. In two subjects there was no significant increase in urine flow.
One of the individuals in this group (O. G.) produced a moderate diuresis with negative pressure breathing when maintained on twice the usual amount of hypotonic saline. The other subject in this group (C. B.) had difficulty voiding at 15minute and even half-hour intervals when repeat

TABLE I

Summary of sixteen experiments showing urine flow, sodium excretion, potassium excretion, and $p H$ before, during, and after negative pressure breathing (NPB)

\begin{tabular}{|c|c|c|c|c|c|c|c|c|c|c|c|c|}
\hline \multirow[b]{2}{*}{ Subject } & \multicolumn{3}{|c|}{$\begin{array}{l}\text { Urine flow } \\
c c . / 15 \text { min. }\end{array}$} & \multicolumn{3}{|c|}{$\begin{array}{l}\text { Urine sodium } \\
m E q . / 15 \text { min. }\end{array}$} & \multicolumn{3}{|c|}{$\begin{array}{l}\text { Urine potassium } \\
m E q . / 15 \text { min. }\end{array}$} & \multicolumn{3}{|c|}{ Urine $\mathrm{pH}$} \\
\hline & Before† & NPB & $\overline{\text { After } \S}$ & Before & NPB & After & Before & NPB & After & Before & NPB & After \\
\hline $\begin{array}{l}\text { H. S. } \\
\text { H.S.* } \\
\text { J. R. } \\
\text { J. R.* } \\
\text { E. M. (Fig. 1) } \\
\text { E. M.* (Fig. 2) } \\
\text { E. M.* (Fig. 3) } \\
\text { C. B. } \\
\text { W. W. } \\
\text { W. W.* } \\
\text { W. W.* } \\
\text { O. G. } \\
\text { O. G.* } \\
\text { J. B. } \\
\text { J. B.* } \\
\text { J. Y. }\end{array}$ & $\begin{array}{l}20 \\
13 \\
20 \\
16 \\
29 \\
20 \\
50 \\
11 \\
19 \\
12 \\
21 \\
9 \\
55 \\
50 \\
60 \\
45\end{array}$ & $\begin{array}{r}84 \\
141 \\
33 \\
64 \\
121 \\
109 \\
190 \\
16 \\
143 \\
86 \\
132 \\
12 \\
77 \\
103 \\
104 \\
87\end{array}$ & $\begin{array}{l}16 \\
19 \\
21 \\
22 \\
29 \\
22 \\
37 \\
10 \\
17 \\
19 \\
21 \\
10 \\
19 \\
41 \\
34 \\
25\end{array}$ & $\begin{array}{l}2.2 \\
1.3 \\
2.7 \\
2.6 \\
3.5 \\
2.6 \\
3.6 \\
2.6 \\
2.5 \\
2.2 \\
2.4 \\
1.7 \\
1.3 \\
3.9 \\
5.2 \\
5.2\end{array}$ & $\begin{array}{l}1.1 \\
1.0 \\
3.2 \\
3.2 \\
3.1 \\
2.4 \\
3.0 \\
2.7 \\
3.0 \\
2.1 \\
2.6 \\
1.7 \\
1.8 \\
3.9 \\
3.0 \\
5.6\end{array}$ & $\begin{array}{l}2.5 \\
2.4 \\
2.7 \\
2.8 \\
3.5 \\
2.6 \\
3.0 \\
2.1 \\
2.3 \\
2.6 \\
2.7 \\
1.7 \\
1.9 \\
2.7 \\
3.4 \\
3.3\end{array}$ & $\begin{array}{l}\overline{0.5} \\
\bar{Z} \\
\overline{ } \\
\overline{1.0} \\
\overline{-} \\
\overline{-} \\
0.5 \\
0.5 \\
0.8 \\
0.7 \\
0.5 \\
0.5\end{array}$ & $\begin{array}{l}\overline{0.8} \\
= \\
\overline{-} \\
\overline{1.0} \\
\overline{-} \\
\overline{0.5} \\
0.5 \\
1.0 \\
0.6 \\
0.5 \\
0.7\end{array}$ & $\begin{array}{l}\overline{0.7} \\
\overline{-} \\
\overline{-} \\
\overline{0.5} \\
\overline{-} \\
\overline{0.4} \\
0.5 \\
0.7 \\
0.2 \\
0.4 \\
0.2\end{array}$ & $\begin{array}{l}\overline{5.9} \\
\overline{7.4} \\
6.0 \\
5.8 \\
7.3 \\
5.5 \\
7.1 \\
6.7 \\
6.8 \\
5.7 \\
6.2 \\
6.7 \\
6.7 \\
6.9\end{array}$ & $\begin{array}{l}\overline{5.6} \\
\overline{7.9} \\
6.0 \\
6.7 \\
7.1 \\
5.5 \\
7.1 \\
6.9 \\
6.8 \\
6.0 \\
6.7 \\
6.8 \\
6.7 \\
6.7\end{array}$ & $\begin{array}{l}\overline{6} \\
6.6 \\
7.7 \\
6.0 \\
6.6 \\
6.7 \\
5.5 \\
6.8 \\
7.0 \\
6.8 \\
6.0 \\
6.7 \\
6.2 \\
6.7 \\
6.6\end{array}$ \\
\hline
\end{tabular}

* Repeat experiments in the same subject.

+15 -minute period immediately before NPB.

Maximum urine flow for 15-minute period during NPB.

15-minute period 30 to 45 minutes after cessation of NPB. 
studies were attempted. In none of the experiments was there a significant increase in total urine sodium or potassium excretion. In general, even with a marked diuresis, the urine $\mathrm{pH}$ was not altered or was inconsistently changed and in only one case did it increase 0.9 of a $\mathrm{pH}$ unit.

The creatinine clearance increased during the early portion of the exposure to negative pressure breathing in some subjects, but returned to control values as this type of breathing was continued and in other cases the diuresis occurred without an alteration in this clearance at any time. In ten experiments the average endogenous creatinine clearance changed from a control value of $134 \mathrm{cc}$. per minute to $140 \mathrm{cc}$. per minute with the maximum diuresis. The pulse rate and arterial pressure remained constant before, during, and after the period of decreased intrathoracic pressure. The respiratory rate was also unaltered or was inconsistently changed so that the average rate was 14 per minute during the control period and 13 per minute during negative pressure breathing. None of the subjects had any of the symptoms or signs associated with hyperventilation.

\section{DISCUSSION}

The results of this study indicate that continuous negative pressure breathing is associated in man with a water diuresis. Under the conditions of the experiment an increase in urine flow occurred without significant alteration of the urine $\mathrm{pH}$ or sodium and potassium excretion. That this was not a chance finding or a conditioned response was demonstrated in the six control studies in which a spontaneous diuresis did not occur after the urine flow was consistently below $60 \mathrm{cc}$. per 15 minutes during the portion of the day in which the subjects were ordinarily exposed to negative pressure breathing. This type of breathing was not uncomfortable so that the increased urine volume can not be similar to the diuresis reported in some stress situations (10). Moreover, the observation of a diuresis with negative pressure breathing in anesthetized animals would seem to exclude these two factors.

Although the respiration was not markedly affected in these human studies, an increase in respiratory rate was frequently noted in the animal experiments when the intrathoracic pressure was decreased (6) so that the possibility of a respiratory alkalosis could not be completely eliminated. Hyperventilation has been reported to be associated with a diuresis in which the urine becomes markedly alkaline and the excretion of sodium and potassium is increased two to five fold (11-13). In contrast, the urine $\mathrm{pH}$ was unaltered or inconsistently changed and the urine sodium and potassium excretion was not increased during the diuresis of negative pressure breathing in man. This evidence demonstrates that the increased urine flow is not the result of a respiratory alkalosis as may occur with hyperventilation. It is of interest in this regard that a water diuresis occurs with hyperventilation on 5 to 7 per cent carbon dioxide without a respiratory alkalosis (14). The mechanism of this type of diuresis was not fully understood, although it was suggested that a mechanical stimulus may have initiated the increased urine flow.

With positive pressure breathing the cardiac output, as measured with the ballistocardiograph, is decreased when the pressure used is two to three times that employed in these studies (i.e., 30 to 40 $\mathrm{mm} . \mathrm{Hg}$ ) (15). Drury, Henry, and Goodman thought that this alteration in the circulation may have contributed in part to the oliguria which they observed with continuous positive pressure breathing (7). It might be postulated that negative pressure breathing increased the cardiac output and that this directly or indirectly initiated a diuresis, but in anesthetized animals at least, the cardiac output does not increase (4). With positive pressure breathing the urea clearance is also decreased (7), but with negative pressure breathing the creatinine clearance is essentially unaltered. While a decrease in cardiac output and glomerular filtration rate may account at least in part for the oliguria of positive pressure breathing, an increase in either of these two hemodynamic factors does not seem to be associated with the diuresis of negative pressure breathing.

The effect of a change in intrathoracic pressure on the distribution of the blood volume and the distension of various portions of the cardiovascular system has been discussed in the previous report of animal experiments (6). In that paper the anatomical studies of Nonidez which demonstrated nervous endorgans in the walls of the thoracic vena cava, pulmonary veins, and auricles of animals $(16,17)$ and the physiological investigations of 
stretch receptor areas in the cardiovascular system within the thorax (18-23) have been reviewed. It was postulated that the diuresis associated with negative pressure breathing in animals was in response to a distension of some or all of these regions within the thorax (6). This same mechanism, it is believed, may account for the diuresis observed in these human experiments. The exact manner in which such a stimulus finally leads to a diuresis is not certain, but it must involve the central nervous system and the antidiuretic hormone of the posterior pituitary gland. The role of the antidiuretic hormone is suggested from the present study because of the unaltered electrolyte excretion and the gradual onset of the diuresis and its gradual cessation.

Recently, a great deal of interest has been shown in the possible demonstration of volume receptors in the body which initiate alterations in renal function. Some of these reports have been concerned with the excretion of electrolytes which accompany a change in blood volume or in its distribution (24-29). It is pertinent to this discussion and the concept presented to point out the situations in which an increase in blood volume in the cardiovascular system in the thorax is associated with a water diuresis. Strauss, Davis, Rosenbaum, and Rossmeisl have reported that a water diuresis occurs with the infusion of saline into recumbent subjects, but it does not occur with infusions into seated subjects (30). They postulate as a result of these experiments that there may be volume receptors in the cephalad portion of the body. Welt, Orloff, and Blake have reported a similar diuresis when the plasma volume is expanded with iso-oncotic albumin solutions (31, 32). With the infusion of saline, blood, or plasma in the recumbent animal or man there may also be an increased pressure in the great veins, the right heart, pulmonary circulation, and the left auricle $(33,34)$. Similarly "cold diuresis" may be attributed to this same mechanism since there is engorgement of the pulmonary vascular system as a result of peripheral vasoconstriction (35).

Although the evidence presented does not exclude an extrathoracic vascular effect of negative pressure breathing as the stimulus for a diuresis, this possibility seems unlikely. With the infusion of saline or iso-oncotic albumin solution, negative pressure breathing, and exposure to cold, the ex- trathoracic venous system may be distended or constricted, but all of these situations are associated with some degree of distension of the low pressure portion of the cardiovascular system within the thorax. It is believed, therefore, that further investigation of alterations in renal excretion of water and electrolytes with stimulation of possible volume or stretch receptors in the thoracic cardiovascular system is warranted.

\section{SUMMARY}

The application of continuous negative pressure breathing for a 45-minute period is associated with a water diuresis in normal human subjects. Under the conditions of these experiments the increased water excretion occurred without a change in urine $\mathrm{pH}$, total urine sodium and potassium excretion, or endogenous creatinine clearance. It is suggested that the diuresis resulted from stimulation of volume or stretch receptor areas in the cardiovascular system within the thorax.

\section{REFERENCES}

1. Dern, R. J., and Fenn, W. O., The effect of varying pulmonary pressure on the arterial pressures in man and anesthetized cats. J. Clin. Invest., 1947, 26, 460.

2. Holt, J. P., The collapse factor in the measurement of venous pressure. The flow of fluid through collapsible tubes. Am. J. Physiol., 1941, 134, 292.

3. Holt, J. P., The effect of positive and negative intrathoracic pressure on peripheral venous pressure in man. Am. J. Physiol., 1943, 139, 208.

4. Holt, J. P., The effect of positive and negative intrathoracic pressure on cardiac output and venous pressure in the dog. Am. J. Physiol., 1944, 142, 594.

5. Rahn, H., Otis, A. B., Chadwick, L. E., and Fenn, W. O., The pressure-volume diagram of the thorax and lung. Am. J. Physiol., 1946, 146, 161.

6. Gauer, O. H., Henry, J. P., Sieker, H. O., and Wendt, W. E., The effect of negative pressure breathing on urine flow. J. Clin. Invest., 1954, 33, 287.

7. Drury, D. R., Henry, J. P., and Goodman, J., The effects of continuous pressure breathing on kidney function. J. Clin. Invest., 1947, 26, 945.

8. Wolf, A. V., The retention and excretion of continuously administered salt solutions. Am. J. Physiol., 1945, 143, 572.

9. Bonsnes, R. W., and Taussky, H. H., On the colorimetric determination of creatinine by the Jaffe reaction. J. Biol. Chem., 1945, 158, 581. 
10. Hinkle, L. E., Jr., Edwards, C. J., and Wolf, S., The occurrence of diuresis in humans in stressful situations and its possible relation to the diuresis of early starvation. J. Clin. Invest., 1951, 30, 809.

11. Collip, J. B., and Backus, P. L., The effect of prolonged hyperpnoea on the carbon dioxide combining power of the plasma, the carbon dioxide tension of alveolar air and the excretion of acid and base phosphate and ammonia by the kidney. Am. J. Physiol., 1920, 51, 568.

12. Stanbury, S. W., and Thomson, A. E., The renal response to respiratory alkalosis. Clin. Sc., 1952, 11, 357.

13. McCance, R. A., and Widdowson, E. M., The response of the kidney to an alkalosis during salt deficiency. Proc. Roy. Soc., London, s.B, 1936, 120, 228.

14. Barbour, A., Bull, G. M., Evans, B. M., Jones, N. C. H., and Logothetopoulos, J., The effect of breathing 5 to $7 \%$ carbon dioxide on urine flow and mineral excretion. Clin. Sc., 1953, 12, 1.

15. Otis, A. B., Rahn, H., Brontman, M., Mullins, L. J., and Fenn, W. O., Ballistocardiographic study of changes in cardiac output due to respiration. J. Clin. Invest., 1946, 25, 413.

16. Nonidez, J. F., Identification of the receptor areas in the venae cavae and pulmonary veins which initiate reflex cardiac acceleration (Bainbridge's reflex). Am. J. Anat., 1937, 61, 203.

17. Nonidez, J. F., Studies on the innervation of the heart. II. Afferent nerve endings in the large arteries and veins. Am. J. Anat., 1941, 68, 151.

18. McDowall, R. J. S., A right auricular pressor reflex. J. Physiol., 1934, 81, 5P.

19. Bainbridge, F. A., The influence of venous filling upon the rate of the heart. J. Physiol., 1915, 50, 65 .

20. Schwiegk, H., Der Lungenentlastungsreflex. Pflüger's Arch. f. d. ges. Physiol., 1935, 236, 206.

21. Parin, V. V., The rôle of pulmonary vessels in the reflex control of the blood circulation. Am. J. M. Sc., 1947, 214, 167.

22. Jarisch, A., and Zotterman, Y., Depressor reflexes from the heart. Acta physiol. Scandinav., 1948, 16, 31.

23. Aviado, D. M., Jr., Li, T. H., Werner, K., Schmidt, C. F., Turnbull, G. L., Piskin, G. W., Hess, M. E., and Weiss, A. J., Respiratory and circulatory reflexes from the perfused heart and pulmonary circulation of the dog. Am. J. Physiol., 1951, 165, 261.

24. Lewis, J. M., Jr., Buie, R. M., Sevier, S. M., and Harrison, T. R., The effect of posture and of con- gestion of the head on sodium excretion in normal subjects. Circulation, 1950, 2, 822.

25. Epstein, F. H., Post, R. S., and McDowell, M., The effect of an arteriovenous fistula on renal hemodynamics and electrolyte excretion. J. Clin. Invest., 1953, 32, 233.

26. Viar, W. N., Oliver, B. B., Eisenberg, S., Lombardo, T. A., Willis, K., and Harrison, T. R., The effect of posture and of compression of the neck on excretion of electrolytes and glomerular filtration: further studies. Circulation, 1951, 3, 105.

27. Epstein, F. H., Goodyer, A. V. N., Lawrason, F. D., and Relman, A. S., Studies of the antidiuresis of quiet standing: The importance of changes in plasma volume and glomerular filtration rate. $\mathrm{J}$. Clin. Invest., 1951, 30, 63.

28. Wilkins, R. W., Culbertson, J. W., Burrows, B. A., Tinsley, C. M., Judson, W. E., and Burnett, C. H., Antidiuresis and renal vasoconstriction following venous congestion of the limbs in normal, hypertensive, and splanchnicectomized subjects. J. Clin. Invest., 1949, 28, 819.

29. Farber, S. J., Alexander, J. D., and Eichna, L. W., Renal hemodynamics and salt and water excretion during induced congestion of the inferior vena cava of man. J. Clin. Invest., 1951, 30, 638.

30. Strauss, M. B., Davis, R. K., Rosenbaum, J. D., and Rossmeisl, E. C., "Water diuresis" produced during recumbency by the intravenous infusion of isotonic saline solution. J. Clin. Invest., 1951, 30, 862 .

31. Welt, L. G., and Orloff, J., The effects of an increase in plasma volume on the metabolism and excretion of water and electrolytes by normal subjects. J. Clin. Invest., 1951, 30, 751.

32. Orloff, J., and Blake, W. D., Effects of concentrated salt-poor human albumin on metabolism and excretion of water and electrolytes in dogs. Am. J. Physiol., 1951, 164, 167.

33. Doyle, J. T., Wilson, J. S., Estes, E. H., and Warren, J. V., The effect of intravenous infusions of physiologic saline solution on the pulmonary arterial and pulmonary capillary pressure in man. J. Clin. Invest., $1951,30,345$.

34. Henry, J. P., Gauer, O. H., Sieker, H. O., and Wendt, W. E., Pressure-volume relationship in the lowpressure side of the cardiovascular system. Am. J. Physiol., 1952, 171, 735.

35. Glaser, E. M., The effects of cooling and warming on the vital capacity, forearm and hand volume, and skin temperature of man. J. Physiol., 1949, 109, 421. 